\title{
Comparison between TRM and FRP strengthening systems at preventing buckling failure of brick masonry walls
}

\section{Comparación entre los sistemas de refuerzo TRM y FRP en la prevención del colapso por pandeo de muros de fábrica}

\author{
$\underline{\text { E. Bernat-Maso }}^{(*)}$, C. Escrig ${ }^{(*)}$, L. Gil ${ }^{(*)}$
}

\section{ABSTRACT}

Fibre Reinforced Polymer (FRP) and Textile Reinforced Mortar (TRM) have been studied, compared and applied to strengthen brick masonry walls. The comparison of their performance against second order bending effects is addressed in this paper for the first time. Experimental and analytical data from previous researches and new analytical data for $T R M$ cases are summarised, ordered and systematically compared to analyse the structural response of strengthened brick masonry walls. The results show a similar performance for both systems in terms of load bearing capacity and in-plane response. However, TRM strengthened cases showed greater lateral deformation than FRP ones.

Keywords: Fabrics; laminates; strengthening; experimental; analytical.

\section{RESUMEN}

Materiales tipo Fibre Reinforced Polymer (FRP) y Textile Reinforced Mortar (TRM) han sido estudiados, comparados y aplicados para reforzar muros de fábrica de ladrillo. La comparación de su comportamiento frente a efectos de flexión de segundo orden se abordada en este artículo por primera vez. Datos experimentales y analíticos de investigaciones previas y nuevos datos analíticos para los casos de TRM son resumidos, ordenados y sistemáticamente comparados para analizar la respuesta estructural de los muros de fábrica de ladrillo reforzados. Los resultados muestran un comportamiento similar de los dos sistemas respecto su capacidad de carga y su respuesta en el plano. Los casos reforzados con TRM mostraron desplazamientos laterales superiores a los reforzados con FRP.

Palabras clave: Tejidos; laminados; refuerzo; experimental; analítico.

(*) Department of Strength of Materials and Engineering Structures. Universitat Politècnica de Catalunya. Colom, 11. o8222 Terrassa, Spain.

Persona de contacto/Corresponding author: ernest.bernat@upc.edu (E. Bernat-Maso)

Cómo citar este artículo/Citation: Bernat-Maso, E., Escrig, C., Gil, L. (2016). Comparison between TRM and FRP strengthening systems at preventing buckling failure of brick masonry walls. Informes de la Construcción, 68(543): e157, doi: http://dx.doi.org/10.3989/ic.16.056. Licencia / License: Salvo indicación contraria, todos los contenidos de la edición electrónica de Informes de la Construcción se distribuyen bajo una licencia de uso y distribución Creative Commons Attribution License (CC BY) Spain 3.o. 


\section{INTRODUCTION}

Load bearing brick masonry walls are a common structural element among in service buildings worldwide. Although concrete and steel construction have replaced the masonry technology nowadays, there is still a large number of buildings which are supported by unreinforced masonry walls. Usually, these are old buildings which are expected to require upgrading interventions to extend their life-cycle, to adapt their performance to new structural codes or to change their use. Thus, strengthening techniques are necessary. This need is plenty justified from an environmental and economic point of view, even more if considering the weight that these structural elements have in the current cities. To provide a general vision of this significance, notice that $75 \%$ of the buildings of the European city of Barcelona are supported by load-bearing masonry walls (1).

Among the different strengthening technologies, the ones which use composite materials are becoming more popular. These, see Garmendia et al. (2), Garcia (3) and Bernat-Masó (4), are aimed to increase the tensile performance of the masonry by bonding a high strength composite to the original structure. The Fibre Reinforced Polymer (FRP) and the Textile Reinforced Mortar (TRM) are the most visible examples of these technologies. FRP is a composite material made of high strength fibres (carbon, glass, aramid, etc.) embedded into an organic matrix (usually an epoxy resin), whereas $T R M$ is a composite material consisting of high performance fibres presented as a grid and embedded into a cementitious matrix (usually a mortar).

Concerning the application of FRP or TRM on masonry structures, the studies are almost limited to shear and bending configurations. The work by Papanicolaou et al. (5) about the effectiveness of TRM at strengthening masonry walls in front of seismic actions has to be highlighted. In addition, Augenti et al. (6) analysed the influence of TRM on the in-plane shear response and Petersen (7) studied the performance of FRP at strengthening unreinforced masonry panels against in-plane shear. Regarding the works about the bending configuration, the research by Hamed and Rabinovitch (8) focused on the lateral out-of-plane strength of FRP strengthened masonry walls has to be highlighted together with the study of the TRM effectiveness to strengthen masonry walls against outof-plane cyclic loads presented by Harajli et al. (9).

However, the load bearing masonry walls are mainly subjected to vertical compressive forces. In addition, these forces transmitted by roofs or floors are not always centred into the thickness of the wall, which might contribute, together with the slenderness, to develop second order bending effects reaching a bending/buckling mixed failure for unreinforced brick masonry load bearing walls. Thus, strengthening these structures against second order effects is essential.

Focusing on the calculation methodologies used to predict the ultimate load bearing capacity of FRP or TRM strengthened masonry walls, it has been noticed that there are analytical tools described in the literature which might provide a starting point for future developments. Among them, the work by Caggiano et al. (10) is significant for the analytical methodology presented to calculate the response of FRP laminates bonded on brittle substrates. Finally, the work by Martínez et al. (11) has to be highlighted because it focuses on the calculation of FRP strengthened masonry against bending efforts.

Different comparisons between FRP and TRM might be found in a literature review. Most of them are referred to concrete structures, like the work by Triantafillou and Papanicolaou (12) who compared these two systems in regard with the organic/inorganic nature of the matrix. In addition, Kurtz and Balaguru (13) compared the flexural response of reinforced concrete $(R C)$ beams strengthened with laminates using organic and inorganic matrixes. Similarly, Toutanji and Deng (14) applied fibre grids embedded into organic and inorganic matrixes to strengthen $R C$ beams subjected to flexural loads. Less researches have been performed to compare the application of FRP or TRM on masonry. Among these, the researches carried out by Papanicolaou et al. (15) and Papanicolaou et al. (16) have to be highlighted because of the comprehensive information provided and for standing up for the fact that TRM is more suitable for masonry structures than $F R P$ due to physical compatibility reasons. In addition, the effectiveness of FRP and TRM are compared when applied to strengthen masonry walls against in-plane and lateral loads in these works.

Taking all this bibliographic information into account it is necessary to carry out a comparison study between the performance of FRP and TRM at strengthening load bearing masonry walls against the second order bending effects developed under eccentric compressive loads. Hence, the research presented herein is aimed to cover this particular knowledge gap, providing information to correctly choose the most suitable strengthening system depending on the specific expectations of an intervention. The particular objectives are: a) performing a qualitative comparison of the performance of $T R M$ and $F R P$ at preventing the mixed bending/buckling failure, paying special attention on the experimentally determined out-of-plane and in-plane deformations; and b) adjusting an analytical method to calculate TRM strengthened walls and apply it to FRP cases too with the aim of carrying out a quantitative comparison to determine the capacity of the proposed methodology to predict the load-bearing capacity of walls subjected to eccentric compressive loads.

To achieve this main goal, an experimental campaign, including 26 full scale walls, has been carried out and it has been completed with an analytical analysis of the structural problem taking into account both FRP and TRM strengthening possibilities and comparing their performance with a comprehensive range of evidences.

Finally, it has to be remarked that the proposed analytical method is applied on TRM strengthened masonry walls for the first time.

\section{EXPERIMENTAL CAMPAIGN}

Load bearing tests on twenty-six full scale walls were carried out in two different phases. The first one comprised eleven walls: two control walls and nine walls strengthened with different TRM systems. The second phase comprised fifteen walls strengthened with FRP. The details of these experimental campaigns might be found in Bernat et al. (17) for the TRM strengthened ones and in Bernat-Maso et al. (18) for the cases strengthened with FRP. Nevertheless, the key features 
of these experimental tasks are briefly presented in this section to provide the information required to understand the comparison between FRP and TRM strengthening systems. In particular, the study is focused on the application of these strengthening products with the aim of limiting the influence of the second order bending effects.

\subsection{Materials and Specimens}

Although all masonry walls were built with the same materials, a standard brick-layering mortar $\mathrm{M} 7.5$ and solid fired clay bricks, the experimental characterisation of the masonry showed that the walls of the two phases had different compressive strengths $\left(f_{m}\right): 10.8 \mathrm{MPa}$ for the walls of the first phase - control and TRM strengthened - and 18.1 MPa for the FRP strengthened ones. However, the flexural strength of the masonry $\left(f_{x}\right)$ and its density $(\rho)$ were experimentally determined and resulted similar for the specimens of both phases and their average values, $0.36 \mathrm{MPa}$ and $1,732 \mathrm{~kg} / \mathrm{m}^{3}$ respectively, were considered. The Young's modulus $\left(E_{m 0}\right)$ of the masonry was experimentally obtained for the cases of the first phase (control and TRM) and deduced from the compressive strength for the walls of the second phase as presented and justified in Bernat-Maso et al. (18).

The real dimensions of each wall are summarised in Table 1. The first two columns of this table describe the case typology and the name of the walls. The next three columns show the width $(b)$, thickness $(t)$ and effective height $\left(H_{e f}\right)$ of each wall. The effective height was measured between the rotation's centres of the two hinges placed to set the pinned-pinned configuration as described later on in section 2.2. The last three columns summarise the mortar type, the number and typology of fibre grids embedded into the TRM and the thickness of the TRM ( $\left.t_{T R M}\right)$ for the TRM strengthened walls. Finally, for the FRP strengthened cases, the three last columns show the number of carbon fibre laminates that were installed in horizontal, vertical and inclined direction.

Three different strengthening mortars (a lime based mortar, a Portland based mortar and a pozzolanic mortar) and two fibre grids (a glass fibre grid and a carbon fibre grid) were used

Table 1. Geometry and strengthening system of the tested cases.

\begin{tabular}{|c|c|c|c|c|c|c|c|c|c|c|}
\hline Case & Name & $b(\mathrm{~mm})$ & $t(\mathbf{m m})$ & $H_{e f}(\mathrm{~m})$ & $e(\mathbf{m m})$ & & & & & \\
\hline \multirow{3}{*}{ Ctrl } & W\#13 & 900 & 134 & 1.660 & 31.8 & & & & & \\
\hline & $\mathrm{W} \# 15$ & 895 & 134 & 1.845 & 29.0 & & & & & \\
\hline & & & & & & \multicolumn{2}{|c|}{ Mortar } & \multicolumn{2}{|c|}{ Fibre grid } & $t_{T R M} e(\mathrm{~mm})$ \\
\hline \multirow{10}{*}{$T R M$} & $\mathrm{~W} \# 21$ & 865 & 132 & 1.832 & 30.3 & \multicolumn{2}{|c|}{ Portland-based } & \multicolumn{2}{|c|}{1 glass fibre } & 13.0 \\
\hline & $\mathrm{W} \# 22$ & 872 & 132 & 1.827 & 33.2 & \multicolumn{2}{|c|}{ Portland-based } & \multicolumn{2}{|c|}{1 glass fibre } & 8.0 \\
\hline & W\#23 & 868 & 132 & 1.822 & 33.9 & \multicolumn{2}{|c|}{ Lime-based } & \multicolumn{2}{|c|}{1 glass fibre } & 9.5 \\
\hline & W\#24 & 867 & 132 & 1.840 & $25 \cdot 4$ & \multicolumn{2}{|c|}{ Lime-based } & \multicolumn{2}{|c|}{1 glass fibre } & 9.0 \\
\hline & $\mathrm{W} \# 25$ & 868 & 132 & 1.828 & 32.7 & \multicolumn{2}{|c|}{ Lime-based } & \multicolumn{2}{|c|}{2 glass fibre } & 7.5 \\
\hline & W\#26 & 869 & 132 & 1.823 & 29.7 & \multicolumn{2}{|c|}{ Portland-based } & \multicolumn{2}{|c|}{2 glass fibre } & 8.0 \\
\hline & $\mathrm{W} \# 27$ & 873 & 132 & 1.822 & 30.4 & \multicolumn{2}{|c|}{ Pozzolana-based } & \multicolumn{2}{|c|}{1 carbon fibre } & 8.0 \\
\hline & $\mathrm{W} \# 28$ & 871 & 132 & 1.828 & 23.7 & \multicolumn{2}{|c|}{ Pozzolana-based } & \multicolumn{2}{|c|}{1 carbon fibre } & 9.0 \\
\hline & W\#29 & 868 & 132 & 1.827 & 31.4 & \multicolumn{2}{|c|}{ Pozzolana-based } & \multicolumn{2}{|c|}{1 carbon fibre } & 11.0 \\
\hline & & & & & & Hor. Lam. & \multicolumn{2}{|c|}{ Vert. Lam. } & \multicolumn{2}{|c|}{ Inc. Lam. } \\
\hline \multirow{15}{*}{$F R P$} & 2VoH_1 & 837 & 127 & 1.798 & 29.5 & $\mathrm{O}$ & \multicolumn{2}{|c|}{2} & \multicolumn{2}{|r|}{$\mathrm{O}$} \\
\hline & 2VoH_2 & 840 & 126 & 1.815 & 31.9 & $\mathrm{O}$ & \multicolumn{2}{|c|}{2} & \multicolumn{2}{|r|}{ o } \\
\hline & 2VoH_3 & 838 & 126 & 1.798 & 29.8 & $\mathrm{O}$ & & & & o \\
\hline & 3VoH_1 & 829 & 126 & 1.811 & 29.7 & O & & & & o \\
\hline & $3 \mathrm{VoH} \_2$ & 833 & 126 & 1.814 & 31.2 & o & & & & o \\
\hline & 3VoH_3 & 837 & 126 & 1.824 & 29.4 & $\mathrm{O}$ & & & & $\mathrm{O}$ \\
\hline & 2V2H_1 & 843 & 126 & 1.788 & 29.4 & 2 & & & & 0 \\
\hline & $2 \mathrm{~V} 2 \mathrm{H} \_2$ & 835 & 124 & 1.792 & 32.7 & 2 & & & & $\mathrm{O}$ \\
\hline & 2V2H_3 & 827 & 125 & 1.797 & 30.1 & 2 & & & & $\mathrm{O}$ \\
\hline & 3V5H_1 & 833 & 124 & 1.777 & 28.7 & 5 & & & & o \\
\hline & 3V5H_2 & 830 & 125 & 1.784 & 27.2 & 5 & & & & $\mathrm{O}$ \\
\hline & 3V5H_3 & 831 & 125 & 1.761 & 27.6 & 5 & & & & o \\
\hline & 3I3I_1 & 826 & 124 & 1.830 & 26.8 & 0 & & & & $\left.1^{\circ} / 119^{\circ}\right)$ \\
\hline & 3I3I_2 & 831 & 125 & 1.831 & 28.8 & $\mathrm{O}$ & & & & $\left.1^{\circ} / 119^{\circ}\right)$ \\
\hline & 3I3I_3 & 827 & 124 & 1.812 & 27.4 & 0 & & & & $\left.1^{\circ} / 119^{\circ}\right)$ \\
\hline
\end{tabular}


to produce the TRM strengthening systems used in this experimental campaign. The flexural and compressive strength of the mortar were experimentally obtained (see BernatMasó (19)) whereas the properties of the fibre grids were provided by the manufacturer. The main mechanical properties of the mortars and fibre grids are summarised in Table 2 and Table 3, respectively. The flexural $\left(f_{x m}\right)$ and compressive $\left(f_{c m}\right)$ strength of the mortars are presented in Table 2. The ultimate elongation of the fibre $\left(\varepsilon_{u l t}^{\text {fibre }}\right)$, the tensile strength of the TRM $\left(T_{u l t}^{T R M}\right)$ and the spacing of the fibre grid are shown in Table 3 for the two fibre grid types.

Carbon FRP laminates of $80 \mathrm{~mm}$ width and $1.2 \mathrm{~mm}$ thick were used to strengthen the corresponding walls. These laminates were bonded to the surface of the walls with an epoxy resin adhesive after preparing the surface of the masonry by impregnating it with a primer. The mechanical properties of the applied carbon FRP are: a tensile strength, $f_{t F R P}$, of 3,100 $\mathrm{MPa}$, a bonding strength, $f_{b F R P}$, of $5.40 \mathrm{MPa}$, a shear strength, $f_{\text {SFRP }}$, of $1.67 \mathrm{MPa}$, a density, $\rho_{\text {FRP }}$, of $160.0 \mathrm{~kg} / \mathrm{m}^{3}$ and a Young's modulus, $E_{F R P}$, of $170 \mathrm{GPa}$.

Five different patterns of carbon $F R P$ strengthening were tested: two vertical laminates $(2 \mathrm{VoH})$, three vertical laminates $(3 \mathrm{VoH})$, two vertical and two horizontal laminates $(2 \mathrm{~V} 2 \mathrm{H})$, three vertical and five horizontal laminates $\left(3 \mathrm{~V}_{5} \mathrm{H}\right)$ and six inclined laminates crossing ones over other in two directions (3I3I). Three walls with each strengthening pattern of FRP were tested (see Table 1).

\subsection{Testing set up and sensors}

All walls were tested in a pinned-pinned configuration in order to set clear boundary conditions. Thus, two hinges were placed, one at each ending of the wall (at the bottom and at the top), to allow the free rotation around axes which were parallel to the wall's surface. The vertical distance between these rotation lines is defined as the effective height, $H_{e f}$, of the walls.

Table 2. Properties of the mortars used in the research. Coefficient of variation in brackets.

\begin{tabular}{|l|c|c|}
\hline \multicolumn{1}{|c|}{ Mortar } & \multicolumn{1}{|c|}{$\begin{array}{c}\text { Flexural } \\
\text { strength, } \\
\boldsymbol{f}_{\boldsymbol{x} \text { (MPa) }} \text { (MPa }\end{array}$} & $\begin{array}{c}\text { Compressive } \\
\text { strength, } \\
\boldsymbol{f}_{\text {cm }} \text { (MPa) }\end{array}$ \\
\hline Brick layering mortar & $1.3(0.89)$ & $3.7(0.63)$ \\
\hline Portland-based mortar & $8.1(0.18)$ & $42.2(0.27)$ \\
\hline Lime-based mortar & $6.6(0.03)$ & $14.5(0.08)$ \\
\hline Pozzolana-based mortar & $9.4(0.10)$ & $34.5(0.08)$ \\
\hline
\end{tabular}

Table 3. Properties of the fibre grids used in the studied TRM solutions. Manufacturer provided values.

\begin{tabular}{|l|c|c|c|}
\hline $\begin{array}{c}\text { Fibre } \\
\text { grid }\end{array}$ & $\begin{array}{c}\text { Ultimate } \\
\text { elongation of the } \\
\text { fibre (\%) }\left(\varepsilon_{u l t}^{\text {fibre }}\right)\end{array}$ & $\begin{array}{c}\text { Tensile strength } \\
\text { of the } \boldsymbol{T R M} \\
(\mathbf{k N} / \mathbf{m})\left(T_{u l t}^{T R M}\right)\end{array}$ & $\begin{array}{c}\text { Grid } \\
\text { dimensions }\end{array}$ \\
\hline Glass & 3 & 45 & $25 \times 25 \mathrm{~mm}$ \\
\hline Carbon & 2.1 & 160 & $10 \times 10 \mathrm{~mm}$ \\
\hline
\end{tabular}

The descending displacement of the top of the wall $(v)$ and the lateral displacement at mid height $(h)$ were measured along the test with potentiometric and laser sensors respectively for all tested walls. In addition, the strain at mid height in vertical direction was measured for all strengthened walls except W\#25, W\#26, W\#28 and W\#29 with one or more strain gages according with the specifications presented in \{FormattingCitation\}(17) and (18). In the cases with more than one measure, the average value is used and presented herein as the comparison result. However, it has to be noticed that the measurements of the strain gages of the FRP strengthened walls of the series $3 \mathrm{~V}_{5} \mathrm{H}$ and $3 \mathrm{I} 3 \mathrm{I}$ were not directly taken at mid-height because laminates crossed ones over others at this level. Instead of this, for the $3 \mathrm{~V}_{5} \mathrm{H}$ cases the measure took place $12.2 \mathrm{~cm}$ over the mid height of the wall. For the 3I3I cases, the measurement was made $18 \mathrm{~cm}$ over the mid height and oriented along an inclined direction (following the direction of the laminate), so the vertical components of these measurements are used for comparison. The particularities arisen from their position and orientation should be taken into account in the discussion section. All strain measurements on FRP laminates were taken at laminates in direct contact with masonry along all their length, so other laminates could cross over them but not under them.

The loading process was force controlled up to the failure of the wall. A high speed video camera was used to record the failure mode and the cracking opening for all cases.

\subsection{Results}

Three failure modes, which were experimentally observed in the 26 full scale tests on the described walls, are presented in Figure 1. The first failure mode (Figure 1a) corresponds to the development of a hinge at mid height due to the tensile failure of the masonry associated to second order bending effects. Similarly, the second failure mode (Figure $1 \mathrm{~b}$ ) is associated with the tensile failure of both masonry and TRM strengthening. This was observed only for walls W\#21 and W\#23. Finally, the most common failure mode among the tested strengthened walls was the compressive/shear failure of the masonry near the ends of the wall. Figure $1 \mathrm{c}$ and Figure $1 \mathrm{~d}$ show this failure pattern for a TRM strengthened wall and a FRP strengthened wall respectively.

Regarding the quantitative results, the maximum applied load for each tested case $\left(F_{\max }^{E X P}\right)$ is normalised over the maximum load $\left(P_{u}\right)$ that the corresponding section could had bear under a uniform compressive stress distribution $\left(P_{u}=f_{m} \cdot \mathrm{b} \cdot \mathrm{t}\right)$. This approach allows the comparison of the experimentally obtained load bearing capacity from walls built with masonries characterised by different compressive strengths. In order to obtain other dimensionless variables, the lateral deflection $(h)$ and the vertical descending displacement $(v)$ are divided by the thickness of the wall $(t)$ and the effective height of the wall $\left(H_{e f}\right)$, respectively. The numerical results of these dimensionless variables at the state of the maximum load are summarised in Table 4 and plotted in Figure 2 and Figure 3.

In Figure 2, the dimensionless variable representing the vertical descending displacement of the walls is plotted versus the dimensionless variable of the applied load for the 


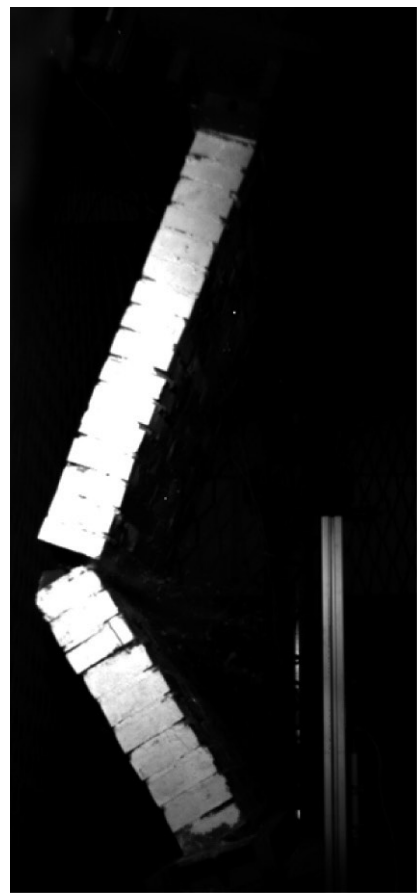

(a)

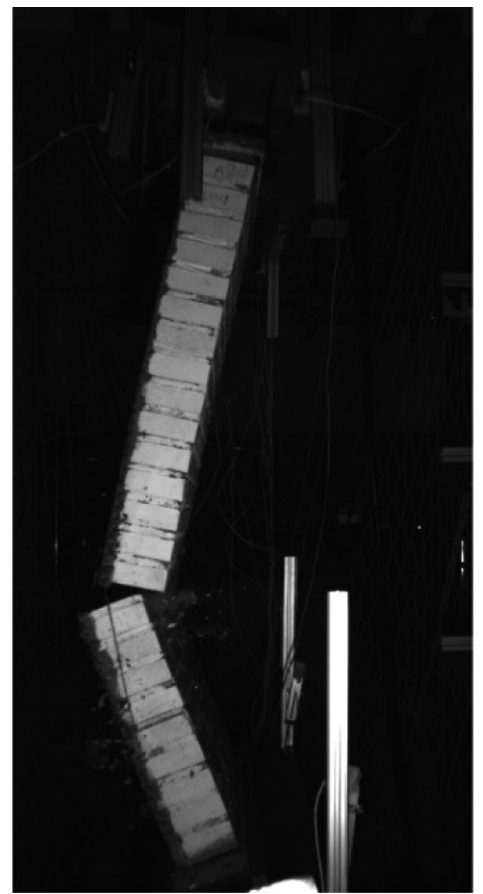

(b)

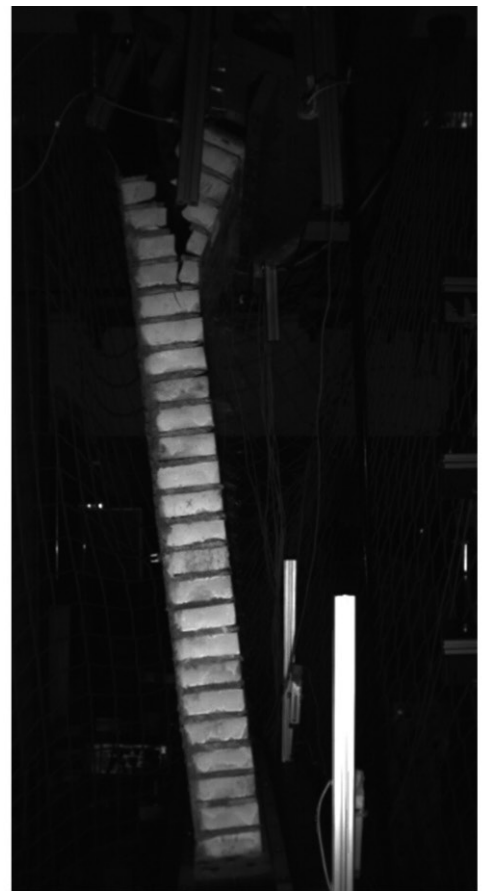

(c)

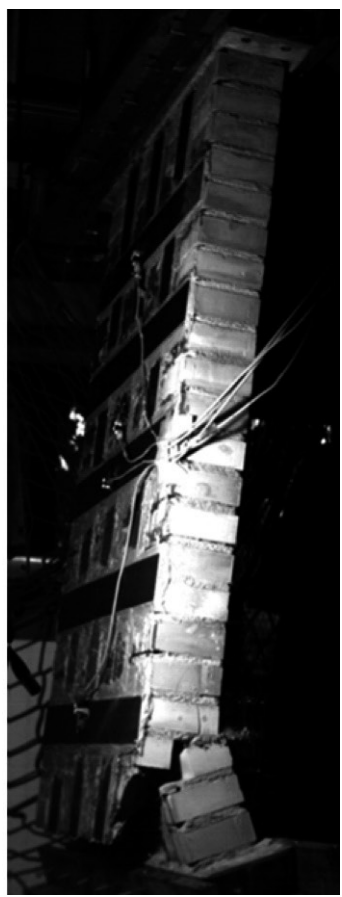

(d)

Figure 1. (a) Failure mode of the unreinforced control walls; (b) of the TRM strengthened walls by TRM tensile failure; (c) of the TRM strengthened walls by masonry compressive/shear failure and (d) failure mode of the FRP strengthened walls by compressive/shear failure of the masonry.

Table 4. Experimental results of the tested walls.

\begin{tabular}{|c|c|c|c|c|}
\hline Case & Name & $\Phi_{\max }(\%)$ & $h_{\max } / t(\%)$ & $v_{\max } / H_{e f}\left(10^{-3}\right)$ \\
\hline \multirow{2}{*}{ Control } & $\mathrm{W} \# 13$ & 6.5 & 9.4 & 2.2 \\
\hline & $\mathrm{W} \# 15$ & 18.4 & 10.1 & 3.2 \\
\hline \multirow{9}{*}{$T R M$} & $\mathrm{~W} \# 21$ & 23.4 & 14.9 & 4.3 \\
\hline & $\mathrm{W} \# 22$ & 25.6 & 15.2 & 3.6 \\
\hline & $\mathrm{W} \# 23$ & 21.1 & 15.6 & 4.2 \\
\hline & $\mathrm{W} \# 24$ & 22.3 & 18.4 & 4.5 \\
\hline & $\mathrm{W} \# 25$ & 32.3 & 18.1 & 4.0 \\
\hline & $\mathrm{W} \# 26$ & 30.4 & 14.5 & 4.6 \\
\hline & $\mathrm{W} \# 27$ & 26.9 & 19.7 & $5 \cdot 7$ \\
\hline & $\mathrm{W} \# 28$ & 24.4 & 10.1 & 3.7 \\
\hline & W\#29 & $25 \cdot 7$ & 10.5 & 4.2 \\
\hline \multirow{15}{*}{$F R P$} & 2VoH_1 & $27 \cdot 3$ & 8.6 & $5 \cdot 7$ \\
\hline & 2VoH_2 & 28.6 & 9.6 & $3 \cdot 7$ \\
\hline & 2VoH_3 & 28.9 & 8.5 & 4.8 \\
\hline & 3VoH_1 & 31.5 & 11.8 & 4.9 \\
\hline & 3VoH_2 & 31.5 & 12.8 & 5.1 \\
\hline & 3VoH_3 & 39.2 & 9.3 & 1.2 \\
\hline & 2V2H_1 & 31.3 & 12.9 & 5.5 \\
\hline & 2V2H_2 & 31.9 & 11.6 & 5.0 \\
\hline & 2V2H_3 & 33.1 & 9.8 & 5.6 \\
\hline & 3V5H_1 & 29.1 & 7.7 & 4.3 \\
\hline & 3V5H_2 & 27.9 & 6.9 & 4.4 \\
\hline & 3V5H_3 & 24.1 & 9.1 & 4.4 \\
\hline & 3I3I_1 & 34.5 & 10.4 & 4.4 \\
\hline & 3I3I_2 & 24.0 & 5.5 & 5.1 \\
\hline & 3I3I_3 & 30.7 & 9.8 & 4.9 \\
\hline
\end{tabular}

control unreinforced walls (URMW), the TRM strengthened walls (TRMW) and the FRP strengthened walls (FRPW). Similarly, the dimensionless lateral displacement is plotted in Figure 3.

Finally, the dimensionless force versus the strain measurements at mid height (considering the limitations explained in section 2.2) is shown in Figure 4. Two differentiated data groups might be observed in this graph. The curves describing the response of the TRM strengthened walls (circles) might be distinguish from those describing the FRP strengthened cases (triangles).

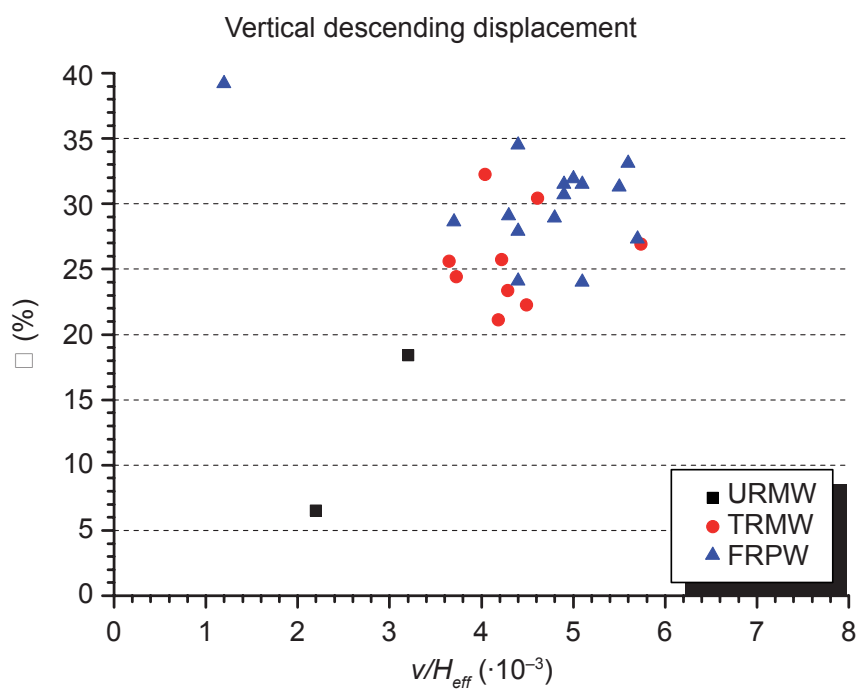

Figure 2. Dimensionless force versus dimensionless vertical displacement of the top of the control walls (URMW), TRM strengthened ones (TRMW) and FRP strengthened walls (FRPW). 


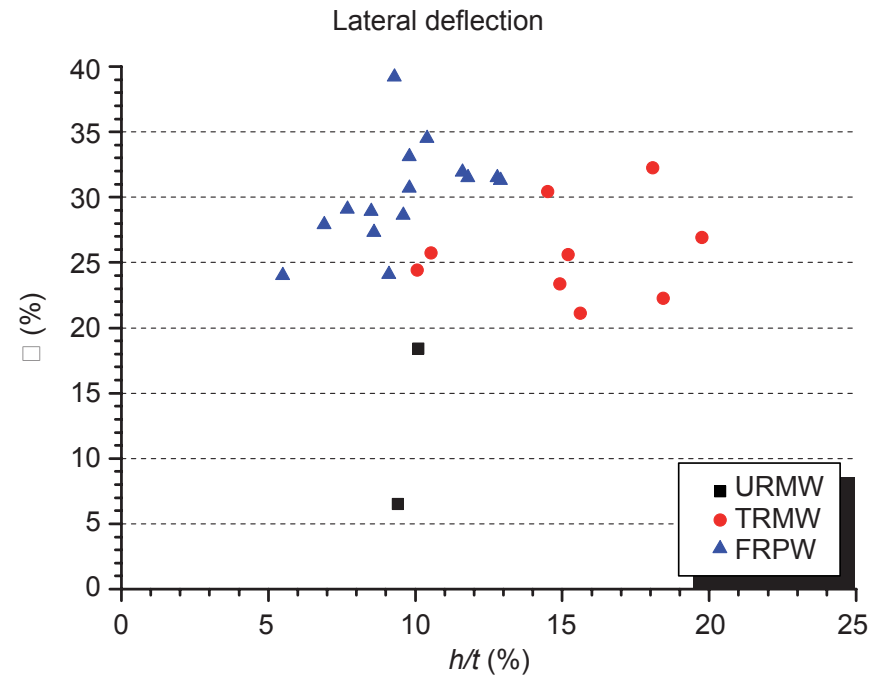

Figure 3. Dimensionless force versus dimensionless lateral displacement at mid height of the control walls (URMW), TRM strengthened ones (TRMW) and FRP strengthened walls (FRPW).

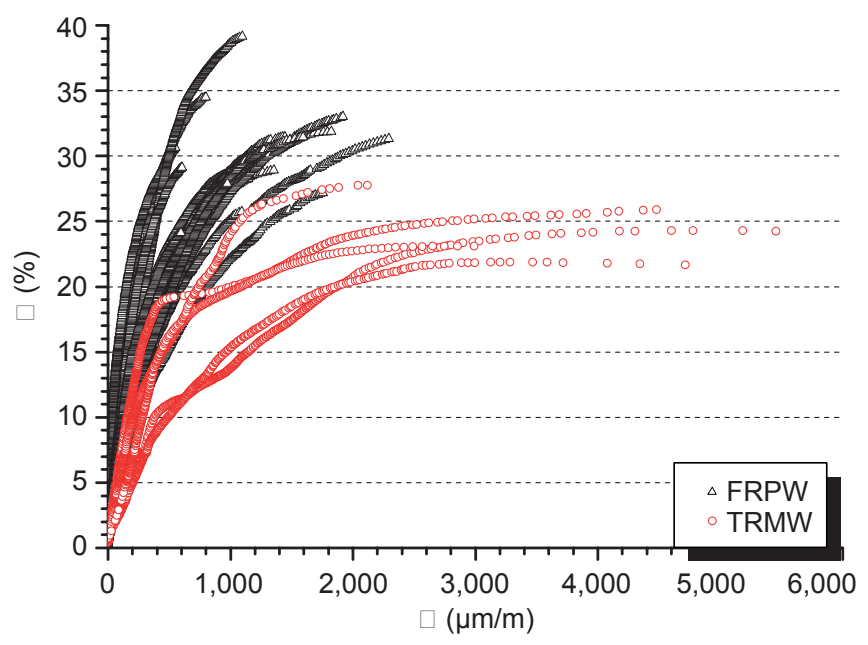

Figure 4. Dimensionless force versus strain at mid height.

\section{ANALYTICAL METHODOLOGY}

In this paper, the methodology to calculate $T R M$ strengthened walls is presented for the first time. For unreinforced cases, the analytical approach and the corresponding results are fully described in Bernat-Maso et al. (4). The application of this methodology to FRP strengthened walls is presented in Bernat-Maso et al. (18). In the next subsections a brief summary of this procedure and the corresponding results are presented to provide comparison data.

On the whole, the considered analytical approach consists on calculating the deflection of the walls considering the second order effects due to the eccentricity of a predefined load and the particular axial rigidity properties of the considered strengthening system (material and installation pattern). This deflection is added to the initial eccentricity to obtain an increased eccentricity at mid height which is associated with a certain combination of axial force and bending moment. Then, this combination of internal efforts is compared with a failure criteria expressed in the same terms (axial force and bending moment) to check if the imposed compressive force is below or over the failure criteria. The failure criteria also depended on the particular strength properties of every considered strengthening. Repeating this calculation for increasing values of the compressive force the intersection between the response curve and the failure criteria curve might be obtained and the corresponding load is set to be the load bearing capacity of the studied wall.

\subsection{Methodology}

The analytical methodology used for calculating the load bearing capacity of unreinforced and strengthened brick masonry walls consists on: a) calculating the response of the wall for a fixed compressive load and taking into account the second order deflection; b) calculating the failure criteria of the section of the wall (compressive crushing of the masonry or tensile failure of the masonry/strengthening system for unreinforced and TRM cases and compressive crushing of the masonry or debonding of the strengthening in the case of the FRP strengthened walls); thus, different failure modes are considered depending on the strengthening material; c) comparing the response of the wall with the failure criteria for different predefined loads to obtain the force which satisfies both definitions (being a possible response of the wall and being a limit failure state), i.e. the load bearing capacity.

Thus, the calculation is based on assuming a failure mode for the structure (depending on the strengthening system) and seeking for the load which meets this failure criteria and satisfies the equilibrium and deformation equations simultaneously. The general required hypothesis are a linear strain distribution and a rectangular stress diagram for the compressed masonry. In addition, for the strengthened cases, it is assumed that the masonry does not bear any tensile stress, that the tensile stresses in the strengthening system might be represented as a punctual load in the section equilibrium and, in the case of the FRP, that the thickness of the adhesive between the masonry and the laminate can be neglected.

The required variables for the calculation depend on the study case. Thus, for the unreinforced walls the geometric variables (effective height, $H_{e f}$, width, $b$, thickness, $t$ and initial eccentricity at mid height, $e_{0}$ ), the compressive, $f_{m}$, and tensile, $f_{x}$, strength of the masonry and the Young's modulus of the masonry, $E_{m 0}$ are necessary. All variables for the unreinforced walls were experimentally obtained. For the carbon $F R P$ strengthened walls, the same variables are necessary except for the tensile strength of the masonry, which is replaced by the properties of the FRP strengthening system provided by the manufacturer: ultimate strain of the FRP, $\varepsilon_{F R P, \text { ult }}=0.029$, the width, $b_{F R P}=80 \mathrm{~mm}$, and thickness, $t_{F R P}=1.2 \mathrm{~mm}$, of the FRP. In addition, the number of laminates installed and the corresponding direction and the Young's modulus of the FRP (summarised in Table 3 and Table 4) are necessary. Moreover, the ultimate strain of the masonry in compression, $\varepsilon_{m, \text { ult }}=0.0035$, is required because the Young's modulus of the masonry is calculated from this last variable (see section 3.1.1 for an analogous example of application on TRM cases). Finally, the properties of the TRM substitute the ones of the FRP for the walls strengthened with the cementitious system. Thus, the flexural strength of the strengthening mortar, $f_{x m}$ (in Table 2), the thickness of the TRM for each wall, $t_{T R M}$ (in Table 1), the ultimate elongation of the fibres embedded into the TRM, $\varepsilon_{u l t}^{\text {fibre }}$ (in Table 3), and the theoretical tensile strength of the 
$T R M, T_{u l t}^{T R M}$ (in Table 3), are necessary. These two last variables for the TRM were provided by the manufacturer but the others were experimentally obtained. Thus, different variables are necessary depending on the analysed strengthening system, which allows taking into account the different tensile response of the strengthening materials applied with specific patterns.

\subsubsection{Application on TRM strengthened walls}

The newly proposed procedure to calculate TRM strengthened wall is presented below:

- The first step for applying this analytical approach on TRM strengthened walls is calculating the parameters which will be kept constant along all the calculation procedure: the Young's modulus of the TRM, $E_{T R M}$ as shown in Eq. [1], ratio of the Young's modulus of the TRM out of the initial Young's modulus of the masonry, $n$ as shown in Eq. [2], and the inertia modulus of the composed section, $I$ Eq. [3]. The initial Young's modulus of the masonry, $E_{m o}$ is calculated as defined in Eq. [4]. The position of the gravity centre of the homogenised section, $x$, is calculated with Eq. [5].

$$
\begin{gathered}
E_{T R M}=\frac{T_{u l t}^{\text {TRM }}}{\varepsilon_{u l t}^{\text {fibre }} t_{\text {TRM }}} \\
n=\frac{E_{\text {TRM }}}{E_{m \mathrm{o}}} \\
I=\frac{1}{12} b t^{3}+b t\left(x-\frac{t}{2}\right)^{2}+\frac{1}{12} n b t_{T R M}^{3}+n b t_{T R M}\left(\frac{t_{T R M}}{2}+t-x\right)^{2} \\
E_{m 0}=\frac{f_{m}}{\varepsilon_{m, u l t}} \\
\frac{t^{2}}{2}+n t_{T R M}\left(t+\frac{t_{T R M}}{2}\right) \\
t+n t_{T R M}
\end{gathered}
$$

- The second step is choosing a value for the compressive eccentric load, $N$. It is recommended to choose a low value for the first calculation and increase it in the following iterations.

- The next step is calculating Eq. [6] the total eccentricity, $e$, which is composed of the initial eccentricity of the load, $e_{0}$, and the second order deflection of the wall at mid-height.

$$
\begin{gathered}
e=e_{o}\left(\frac{1}{\cos \left(\frac{H_{e f}}{2} \sqrt{\frac{N}{E_{m} I}}\right)}\right) \\
E_{m}=E_{m o} \frac{t-c}{t}
\end{gathered}
$$

The Young's modulus of the masonry used in Eq. [6] is updated at each calculation iteration according with Eq. [7], except for the first iteration for which it is assumed that . $c$ is the position of the neutral axis defined in the next step.
- The fourth step of this procedure consist on choosing a failure mode (masonry crushing or tensile failure of TRM) and calculating the position of the neutral axis, $c$ by using the force equilibrium equation in the section and the strain compatibility equation.

- In the case of assuming the compressive failure of the masonry, the corresponding equations are Eq. [8] and Eq. [9]. After obtaining the value of $c$, it has to be checked that $\varepsilon_{\text {TRM }} \leq \varepsilon_{\text {ult }}^{\text {fibre }}$. If this requirement is not fulfilled, the TRM tensile failure has to be assumed.

$$
\begin{gathered}
N=f_{m} b o .8 c-e_{\text {TRM }} b t_{\text {TRM }} E_{\text {TRM }} \\
\frac{e_{m, u l t}}{c}=\frac{e_{\text {TRM }}}{t+\frac{t_{T R M}}{2}-c}
\end{gathered}
$$

In the case of assuming the tensile failure of the TRM, the corresponding equilibrium and compatibility equations are Eq. [10] and Eq. [11]. After obtaining the value of $c$, it has to be checked that $\varepsilon_{m} \leq \varepsilon_{m, u l t}$. If this requirement is not fulfilled, the masonry crushing failure has to be assumed.

$$
\begin{gathered}
N=f_{m} b o .8 c-e_{u l t}^{\text {fibre }} b t_{T R M} E_{T R M} \\
\frac{e_{m}}{c}=\frac{e_{u l t}^{\text {fibre }}}{t+\frac{t_{T R M}}{2}-c}
\end{gathered}
$$

- The next step is calculating Eq. [12] the bending moment, $M$, associated with the position of the neutral axis calculated before, $c$. In the case of supposing the tensile failure of the TRM, it is assumed that $\varepsilon_{\text {TRM }}=\varepsilon_{u l t}^{\text {fibre }}$ in Eq. [12].

$$
M=f_{m} b o .8 c(x-0.4 c)+e_{T R M} b t_{T R M} E_{T R M}\left(t+\frac{t_{T R M}}{2}-x\right)
$$

Finally, the eccentricity associated with the bending moment, $e_{M}$, is calculated using Eq. [13].

$$
e_{M}=\frac{M}{N}
$$

and the total eccentricity due to second order bending effects, $e$, is compared with the eccentricity associated with the bending moment, $e_{M}$. If these two eccentricities are equal, the value of the force initially assumed, $N$, is the load-bearing capacity of the studied wall. Otherwise, the value of $N$ is changed and the procedure is restarted from the step b) up to the convergence between $e$ and $e_{M}$.

\section{RESULTS}

The analytical results of the unreinforced control cases show that their failure cause is reaching the tensile strength of the masonry. In contrast, for all strengthened cases the analytical approach points out that the collapse of the structure is associated with the compressive failure of the masonry.

According with the quantitative results of the analytical approach (see Table 5) both strengthening systems were similarly effective at preventing the bending/buckling failure associated with the eccentric compressive loads. In com- 
Table 5. Results of the analytical approach. Load bearing capacity and value of the relative error.

\begin{tabular}{|l|c|c|l|c|c|}
\hline Wall & $\boldsymbol{\Phi}_{\max }$ (\%) & err. (\%) & Wall & $\boldsymbol{\Phi}_{\max }$ (\%) & err. (\%) \\
\hline W\#13 & 4.7 & -29.3 & 2VoH_1 & 25.8 & -11.3 \\
\hline W\#15 & 5.1 & -72.6 & 2VoH_2 & 25.6 & -5.1 \\
\hline Average & 4.9 & -51.0 & 2VoH_3 & 25.7 & -4.5 \\
\hline & & & 3VoH_1 & 26.5 & -1.1 \\
\hline & & & 3VoH_2 & 26.4 & -1.5 \\
\hline Wall & $\boldsymbol{\Phi}_{\max }$ (\%) & err. (\%) & 3VoH_3 & 26.3 & -21.0 \\
\hline W\#21 & 29.0 & 23.9 & 2V2H_1 & 25.9 & -2.9 \\
\hline W\#22 & 26.8 & 4.7 & 2V2H_2 & 25.5 & -6.1 \\
\hline W\#23 & 26.1 & 23.7 & 2V2H_3 & 25.5 & -9.4 \\
\hline W\#24 & 30.9 & 38.6 & 3V5H_1 & 26.3 & -6.1 \\
\hline W\#25 & 27.3 & -15.5 & 3V5H_2 & 26.4 & -11.1 \\
\hline W\#26 & 29.1 & -4.3 & 3V5H_3 & 26.7 & 29.8 \\
\hline W\#27 & 30.6 & 13.8 & 3I3I_1 & 26.5 & -9.9 \\
\hline W\#28 & 34.1 & 39.8 & 3I3I_2 & 26.5 & 29.4 \\
\hline W\#29 & 30.1 & 17.1 & 3I3I_3 & 26.6 & -1.8 \\
\hline Average & 29.3 & 15.8 & Average & 26.1 & -2.2 \\
\hline
\end{tabular}

parison with the unreinforced walls the load bearing capacity increase was around 6 times. The average relative error was significantly higher for the TRM strengthened cases than for the FRP strengthened ones.

The particular results of the analytical method applied on TRM strengthened walls have to be highlighted because of their novelty. This approach suggested that the proposed analytical approach bring more accurate results for the cases with two fibre grids embedded into the TRM layer (walls W\#25 and W\#26 with an average error of $-9.9 \%$ in contrast with the global error of the TRM cases of $15.8 \%$ ). In addition, the relative error was far lower for the cases strengthened with Portland-based mortar and the general trend was to overestimate the load bearing capacity of the walls strengthened with one fibre layer when comparing with the experimental results. The two cases strengthened with two fibre layers were slightly overestimated by the proposed analytical methodology. Finally, the average error of the proposed analytical methodology for the TRM strengthened cases was 15.8 $\%$, overestimating the experimental response.

The relative error obtained for both $T R M$ and FRP cases is within the typical scattering range of the experimental results on masonry structures.

\section{DISCUSSION}

The experimental and analytical data presented in the previous sections is compared and discussed to analyse the performance of TRM and FRP at strengthening brick masonry walls against second order bending effects caused by the eccentric application of a compressive load.

Two types of analyse are carried out. First, a qualitative analysis between different strengthening systems, which takes into account that different amount of strengthening fibres and different strengthening patterns have been used. Thus, the numerical results of different strengthening typologies are not directly comparable. Secondly, a quantitative comparison between experimental and analytical results for every tested wall are included.

The first evidence which has to be highlighted is that both studied strengthening systems are extremely effective at enhancing the load bearing capacity of the masonry walls. This evidence, which is common for the two studied approaches (experimental and analytical), might be related with the tensile strength provided by the TRM or FRP. Detailed data about particular comparisons are analysed in the next subsections.

\subsection{Experimental evidences}

Before analysing the experimental results it is important to remind that the compressive strength of the masonry is different for the two phases of the experimental campaign. Because of this, the values of the ultimate load bearing capacity have been normalised as presented in section 2.3 to allow the comparison between them. However, the amount of fibres installed for each strengthening option is not directly comparable. Hence, the analysis presented herein is focused on the general response of the walls and the failure pattern analysis.

Looking into the experimental results with detail it might be observed that almost all strengthened walls showed the same failure mode: masonry compressive/shear collapse near the endings of the wall. Only for two of the TRM strengthened structures (W\#21 and W\#23) the failure mode was similar to that observed in the tests on unreinforced walls, i.e. the mechanism formation. Hence, the failure pattern does not seem to depend on the strengthening system whenever the strengthening material is able to support the tensile efforts without failing.

The two abovementioned exceptions (W\#21 and W\#23) may be due to the in-situ production of the brick masonry and the TRM system, which is associated with the scattering of the mechanical properties of both materials. It is likely that walls W\#21 and W\#23 had greater shear strength than the other walls strengthened with one layer of TRM (W\#22 and W\#24). It is also possible that the quality of the TRM strengthening of these particular walls was poorer than for the comparable ones. Nevertheless, it seems that applying one layer of glass fibre $T R M$ is the minimum required strengthening to change from mechanism failure to masonry compressive/shear collapse near the endings, for the considered walls and loading pattern.

In this way, it has to be noticed that the dimensionless load bearing capacity of the strengthened walls is very similar for all cases, not depending on the strengthening system. This experimental evidence is related with the practical uniformity of the failure mode which affects the masonry. Thus, the variations which could arise from the differences between the strengthening systems are less significant when the critical point is the compressive or shear strength of the masonry wall.

Comparing the structural behaviour of the walls strengthened with the two different systems (FRP and TRM) it might be observed that both technologies show a similar in-plane response (see Figure 2), which is mostly influenced by the compressive mechanical properties of the masonry. In contrast, the lateral out-of-plane response, which mainly depends on 
the strengthening system, shows significant differences. In Figure 3 it is observed that the walls strengthened with TRM have a more flexible response, reaching larger lateral deformations (around the double) than the walls strengthened with $F R P$, which fail for similar lateral deformations than the control walls. Thus, the FRP effectively restrains the lateral movements of the structure but does not significantly increase its load bearing capacity or changes the failure mode. This response might be related with the greater stiffness of the FRP strengthening system in comparison with the TRM option.

The results presented in Figure 4 indicate that the strains at the mid height section, which are oriented in vertical direction, are larger on the surface of the TRM system than on the surface of the FRP laminates. This fact is in agreement with the results presented in Figure 3 because the TRM system needs to develop larger strains to develop larger lateral deformations of the wall. Comparing the two groups of curves (black triangles for the FRP and red circles for the TRM) it is observed that the TRM strengthening system is clearly more flexible than the FRP because larger strains are developed for equivalent applied loads. Nevertheless, it has to be noticed that the qualitative response of both strengthening systems is approximately the same, describing a parabolic strain-force response which is only linear for little loads (for the range of $\Phi \leq 10 \%)$.

\subsection{Analytical evidences}

The obtained analytical results pointed out that all strengthened walls failed for the same cause with independence on the applied strengthening system. Thus, the application of a material which increases the tensile strength of the original structure (TRM or FRP) is useful to avoid the mechanism formation collapse mode, which is so common for the unreinforced cases. In fact, the proposed analytical methodology also predicted the mechanism formation failure for the control walls.

Regarding the analytically calculated load bearing capacity for the strengthened walls, it has to be highlighted that the resistance of the walls was approximately the same independently from the applied strengthening system or the used strengthening configuration. This evidence indicates that the material which controls the failure mode in these walls is always the masonry. Hence, if the tensile resistance of the strengthening system is assured, the masonry becomes the component which should be studied in detail for walls subjected to eccentric compressive loads. This statement is in agreement with the experimental evidences.

In addition, it has to be remarked that the results of the proposed analytical approach for the FRP strengthened walls are really accurate. This is deduced from the littler average relative error showed for the FRP strengthened calculations in comparison with the experimental results (Table 5). This accuracy might be related with the controlled production of the carbon FRP laminates, which increases the representativeness of the provided properties.

Finally, and because it is the first time this analytical methodology is applied on TRM strengthened walls, it is significant to point out that this calculation tool is more accurate for the cases with more fibres embedded into TRM (comparing W\#21 and W\#22 with W\#26, and W\#23 and W\#24 with W\#25) or those which used a mortar with higher tensile strength (comparing W\#21,W\#22 and W\#26 with W\#23-25). This evidence might be justified by the fact that in these particular cases the force developed by the TRM system was greater and was more localised, so the assumption of having a punctual load in comparison with the stress distribution on the masonry section is more representative of the real situation.

\section{CONCLUSIONS}

Experimental and analytical comparisons of the performance of TRM and FRP strengthening systems at enhancing the load bearing capacity of brick masonry walls subjected to eccentric compressive loads have been carried out. The first conclusion, which arises from this research, is that both systems are effective at preventing the mixed bending/buckling failure due to the mechanism formation, which is typical of the unreinforced brick masonry walls subjected to this loading configuration.

The comparison between the walls strengthened with FRP and TRM against mixed bending/buckling phenomena is presented herein for the first time. As a general trend, the specific strengthening systems, which had different axial rigidity for every strengthening case, suppressed the strengthening system-dependent type of failure. Hence, the failure was controlled by the masonry compressive/shear properties most of the analysed walls.

The comparison allows concluding that TRM and FRP strengthened walls reached similar load bearing capacity when the observed failure mode was mostly controlled by the masonry properties. In this line, as long as the in-plane compressive response also depends on the masonry properties, it is analogous for the TRM and FRP strengthened cases. In contrast, the lateral bending response of the walls depended on the applied strengthening system. Thus, the walls which used carbon FRP showed a stiffer response than the ones strengthened with TRM, which presented greater lateral deformations. However, it has to be reminded that the applied strengthening schemes are not compared in terms of equivalent axial rigidity so qualitative comparisons are only possible.

In this line, it has to be remarked that all used calculation approaches (experimental and analytical) indicated that the strengthened walls would fail with the same collapse mode independently from the applied strengthening system.

Finally, it can be concluded that both strengthening systems are suitable for strengthening the studied structures under the loading situations defined. Thus, other parameters like the compatibility with the masonry, the simplicity of the application procedure, the thermal stability or the toxicity of the used products might help to choose between using TRM or FRP.

\section{ACKNOWLEDGEMENTS}

The authors would like to acknowledge the companies who have helped developing the research by providing products: Mapei S.p.A., Ruredil S.p.A. and BASF. We also want to thank the support of COMSA-EMTE Company. The first author also wants to acknowledge the financial support of the Grant 2014 PDJ 00105 from AGAUR, Generalitat de Catalunya, Spain. 


\section{REFERENCES}

(1) Moreno-González, R., Bairán, J.M. (2011). Análisis del comportamiento sísmico de los edificios de obra de fábrica, típicos del distrito Eixample de Barcelona. Informes de la Construcción, 63(524): 21-32, doi: http://doi.org/10.3989/ ic.10.045.

(2) Garmendia, L., San-José, J.T., García, D., Larrinaga, P. (2011). Rehabilitation of masonry arches with compatible advanced composite material. Construction and Building Materials, 25(12): 4374-4385, doi: http://doi.org/10.1016/j. conbuildmat.2011.03.065.

(3) García, D. (2009). Experimental and numerical analysis of stone masonry walls strengthened with advanced composite materials. Bilbao: Escuela de Ingenieria de Bilbao.

(4) Bernat-Maso, E., Gil, L., Roca, P. (2014). Analytical method for the assessment of unreinforced brick masonry walls subjected to eccentric compressive loads. Construction and Building Materials, 73: 180-186, doi: http://doi.org/10.1016/j. conbuildmat.2014.09.105.

(5) Papanicolaou, C., Triantafillou, T., Lekka, M. (2011). Externally bonded grids as strengthening and seismic retrofitting materials of masonry panels. Construction and Building Materials, 25(2): 504-514, doi: http://doi.org/10.1016/j.conbuildmat.2010.07.018.

(6) Augenti, N., Parisi, F., Prota, A., Manfredi, G. (2011). In-Plane Lateral Response of a Full-Scale Masonry Subassemblage with and without an Inorganic Matrix-Grid Strengthening System. Journal of Composites for Construction, 15(4): 578590, doi: http://doi.org/10.1061/(ASCE)CC.1943-5614.0000193.

(7) Petersen, R.B. (2009). In-plane Shear Behaviour of Unreinforced Masonry Panels Strengthened with Fibre Reinforced Polymer Strips. Newcastle (Australia): University of Newcastle.

(8) Hamed, E., Rabinovitch, O. (2010). Lateral out-of-plane strengthening of masonry walls with composite materials. Journal of Composites for Construction, 14(4): 376-387.

(9) Harajli, M.H., ELKhatib, H., Tomas San-Jose, J. (2010). Masonry Walls Strengthened Using Fibre Textile-Mortar System: Experimental Evaluation of Out-of-Plane Cyclic Response. In CSHM-3 (pp. 19-32). Ottawa-Gatineau (Canada).

(10) Caggiano, A., Martinelli, E., Faella, C. (2012). A fully-analytical approach for modelling the response of FRP plates bonded to a brittle substrate. International Journal of Solids and Structures, 49(17): 2291-2300, doi: http://doi. org/10.1016/j.ijsolstr.2012.04.029.

(11) Martínez, S., García, M.D., Gutiérrez, J.P. (2015). Cálculo en agotamiento de secciones de fábrica reforzadas a flexión con láminas de FRP. Informes de la Construcción, 67(540): e118, doi: http://dx.doi.org/10.3989/ic.15.005.

(12) Triantafillou, T.C., Papanicolaou, C.G. (2005). Textile reinforced mortars (TRM) versus fibre reinforced polymers (FRP) as strengthening materials of concrete structures. In Proceedings of the 7th ACI International Symposium on FibreReinforced (FRP) Polymer Reinforcement for Concrete Structures, pp. 99-118. Kansas City (USA).

(13) Kurtz, S., Balaguru, P. (2001). Comparison of inorganic and organic matrices for strengthening of RC beams with carbon sheets. Journal of Structural Engineering, 127: 35-42.

(14) Toutanji, H., Deng, Y. (2007). Comparison between organic and inorganic matrices for RC beams strengthened with carbon fiber sheets. Journal of Composites for Construction, 11(5): 507-513.

(15) Papanicolaou, C.G., Triantafillou, T.C., Karlos, K., Papathanasiou, M. (2006). Textile-reinforced mortar (TRM) versus FRP as strengthening material of URM walls: in-plane cyclic loading. Materials and Structures, 40(10): 1081-1097, doi: http://doi.org/10.1617/s11527-006-9207-8.

(16) Papanicolaou, C.G., Triantafillou, T.C., Papathanasiou, M., Karlos, K. (2007). Textile reinforced mortar (TRM) versus FRP as strengthening material of URM walls: out-of-plane cyclic loading. Materials and Structures, 41(1): 143-157, doi: http://doi.org/10.1617/s11527-007-9226-0.

(17) Bernat, E., Gil, L., Roca, P., Escrig, C. (2013). Experimental and analytical study of TRM strengthened brickwork walls under eccentric compressive loading. Construction and Building Materials, 44(o): 35-47, doi: http://dx.doi.org/10.1016/j. conbuildmat.2013.03.006.

(18) Bernat-Maso, E., Gil, L., Escrig, C. (2015). Analysis of brick masonry walls strengthened with fibre reinforced polymers and subjected to eccentric compressive loads. Construction and Building Materials, 84: 169-183, doi: http://doi. org/10.1016/j.conbuildmat.2015.02.078.

(19) Bernat-Masó, E. (2014). Analysis of unreinforced masonry walls under eccentric axial load. Saarbrücken (Germany): Scholar's Press. 